EGU2020-9406

https://doi.org/10.5194/egusphere-egu2020-9406

EGU General Assembly 2020

(c) Author(s) 2020. This work is distributed under

the Creative Commons Attribution 4.0 License.

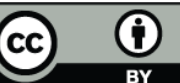

\title{
Pre-eruptive magmatic processes and their timescales revealed by crystal zoning
}

\author{
Helena Albert ${ }^{1}$, Sergio Sainz-Maza ${ }^{1}$, Adelina Geyer ${ }^{2}$, and Carmen López ${ }^{1}$ \\ ${ }^{1}$ Central Geophysical Observatory, IGN, Madrid, Spain \\ ${ }^{2}$ Institute of Earth Sciences Jaume Almera, CSIC, Barcelona, Spain
}

Understanding the processes that occur in the magma plumbing systems prior to eruption and how they relate to monitoring data can lead to improved volcanic hazard assessment. Crystal compositions are witnesses of the architecture and dynamics of the plumbing system, and crystal zoning patterns can inform us of the range of magmatic environments, and of the likely processes that lead to eruption. We have studied the petrology and the geochemistry of the monogenetic historical eruptions occurred in Tenerife (Canary Islands) that come out through the rift zones (NW and NE Rifts) as well as the last mafic intra-caldera monogenetic eruption of Montaña Mostaza (15 ka). The deposits from the NE Rift and the intra-caldera contain complexly zoned olivine crystals suggesting open system and magma mixing, while crystals from the NW Rift are mainly normally zoned. By modelling the zonation patterns of the crystals we have calculated the timescales of the magma intrusions and ascent to the surface. We have found that the magmas erupted along the NW rift are more evolved and vary from basanites to phono-tephrites, while the magmas from the NE rift are basanites recording different mixing events between magma pockets occurred around 1-2 years, 3 months and few days before the eruption. The olivine crystals from the intra-caldera eruption display more variety in the zoning patterns than the eruptions from the rift, suggesting a more complex history. Based on the integration of the petrological and modelling results with gravimetric and geophysical data we propose, at least, three main different ascent histories (paths and timescales) for monogenetic eruptions in Tenerife.

This research has been partially funded by the EUROVOLC project (Horizon 2020 Grant Agreement: 731070). 